\title{
A comparison of the effect of reduced illumina- tion and tinted lenses on stereopis at near
}

\section{Mehta *, P Ramkissoon ** and AM Bhagwanjee***}

* Discipline of Optometry, University of KwaZulu-Natal, PO Box 54001, Durban 4000 South Africa

** PO Box 1097, Newcastle, 2940 South Africa

${ }^{* * *}$ School of Psychology, University of KwaZulu-Natal, PO Box 54001, Durban, 4000 South Africa

*<mehtam@ukzn.ac.za>

**< pauleyes@mweb.co.za>

***< bhagwanjeea@ukzn.ac.za>

\begin{abstract}
Relative depth may be appreciated with the use of one eye using linear perspective, shadows, parallax and texture as monocular cues to depth. Stereopsis, on the other hand, is the direct appreciation of relative depth that requires the use of both eyes to construct a three-dimensional percept from disparate two-dimensional retinal images. The advantage of stereopsis is with respect to complex visual tasks especially that requiring accurate hand-eye coordination.

Tinted lenses are prescribed for a variety of reasons, including but not limited to photophobia, asthenopia, improving colour perception in colour deficient individuals, enhancing cosmesis and protection against glare or harmful radiation and enhancing visual performance as in sports. The aim of this study was to investigate the comparative effects of six specific CR39 tinted spectacle lenses (grade B), and a white CR39 lens, against a no lens condition, on stereoacuity over a range of illumination levels. Illumination was varied with the use of neutral density (ND) filters, while the Titmus Fly Stereotest (TFS) was

used to measure stereoacuity. Participants ( $n=$ 60 ) between the ages of $17-29$ years (mean $=$ $23.58 ; \mathrm{sd}=3.14$ ) were purposively sampled from a clinical practice to participate in this research study.

Using repeated measures ANOVA and appropriate post-hoc multivariate analysis, it was evident that there was a significant decline in stereopsis as the level of illumination decreased, regardless of tint condition; also there was no statistically significant difference in stereopsis between the no lens and white lens conditions at each level of illumination; and stereopsis was significantly superior with the no lens condition compared to all six other tint conditions (grade B), at each level of illumination.

These results indicate that stereoacuity, as measured by the TFS, is adversely affected by a decline in retinal illuminance and by the use of tinted lenses. This information could be utilised to advise patients on the performance implications of the six tinted lenses tested with respect to their effects on stereoacuity under different illumination levels.
\end{abstract}

*BOptom (UDW) CAS (NewEnCo) MOptom (UK)

**BOptom (UDW) CAS (NewEnCo) MPhil (RAU) DPhil (RAU)

${ }^{* * *}$ BA (UDW) BA Hons (UDW) MA (Clin. Psy) (UDW) 


\section{Introduction}

Even though the retinal image is two-dimensional, the world one looks out on is three-dimensional ${ }^{1}$. The three-dimensional shape can be determined by estimating relative depths. Depth perception can be appreciated using monocular cues such as linear perspective, shadows, parallax and texture amongst others ${ }^{2-5}$ as well as binocular cues such as stereopsis ${ }^{6}$. Stereopsis contributes to the judgment of depth and distance while facilitating the recognition of solid objects, with localisation playing a valuable role in a variety of daily tasks ${ }^{2,3}$. Although we have two eyes, we usually have only one visual world ${ }^{7}$. This is made possible by the use of egocentric (knowing the distance and position of an object relative to our body) and oculocentric (quantification of the location of the object within the field of view) axes of localisation ${ }^{1,2}$. This stereoscopic function is due to the frontal positioning of the eyes through the process of evolution in humans ${ }^{1-3}$. The horizontal separation of the two eyes results in relatively small retinal positional differences, giving rise to different principal visual directions for the same object $^{2,4,6,8}$. If this positional difference (retinal disparity) is within Panum's fusional space, it provides significant information about three-dimensional scene structures, giving rise to stereopsis $^{4,6}$. While similar objects stimulating noncorresponding (disparate) retinal points within Panum's fusional area may be fused to give rise to single binocular vision, very dissimilar objects cannot be fused, resulting in suppression, superimposition, binocular rivalry or diplopia ${ }^{6}$.

Fusion is the sensory neural process whereby these two possibly disparate retinal images are associated to produce a single percept in the higher cortical centers, that is, binocular single vision $^{6}$. However, if the horizontal disparity exceeds two degrees and if there is any vertical disparity of over a few minutes of arc, it leads to diplopia ${ }^{1}$. Vergence is the eye movement most commonly associated with fusion ${ }^{1,5}$. Fusion together with vergence eye movements has evolved to support stereopsis ${ }^{8,9}$. It has been reported that there are at least two independent stereopsis mechanisms, one sensitive to chromatic contrast and the other to luminance contrast ${ }^{10}$. Although the information from each mechanism may be combined into a unified percept, in comparing chromatic stereopsis to luminance stereopsis, the former mechanism is less sensitive to contrast, has a more limited disparity range, poorer stereoacuity and poorer ability to encode stereoscopically defined shape than the luminance stereopsis mechanism ${ }^{11}$. Empirical evidence on the effects of illumination on stereopsis indicates that stereoacuity decreases at low levels of retinal illumination ${ }^{12-14}$. A significant decrease in stereoacuity was noted when the value of the ND filter was 1.4 ND (4\% transmission) with TFS $^{12}$. Stereopsis had also been measured under scotopic conditions and was found to be possible in dark adaptation even though it decreased steeply ${ }^{15}$.

The clinical value of stereopsis testing is that it is a good indicator of the overall functioning of both the sensory and motor aspects of the visual system ${ }^{3,5}$. The unit of measure of stereopsis is seconds of arc and the stereoacuity is obtained when the least horizontal disparity evokes the perception of depth ${ }^{2,3}$. Elkington and Frank ${ }^{16}$ report that 60 seconds of arc is considered normal stereoacuity measured at $40 \mathrm{~cm}$, though 15 seconds of arc or better can be measured at 80 $\mathrm{cm}$ using the Frisby test. Good stereopsis at near is required for accurate hand-eye coordination when using tools, threading a needle, performing surgery or even using a computer ${ }^{17-19}$. Reduced stereopsis may cause symptoms of discomfort such as eyestrain, headaches and diplopia ${ }^{3,20}$.

Tests of stereopsis can be broadly divided into two categories: contour stereotests and randomdot stereotests ${ }^{6}$. Random-dot stereotests have no monocular cues so that stereoscopic depth perception can only occur when binocular fusion has occurred. In this case, a process of global stereopsis is used as evaluation, with correlation of corresponding retinal and disparate points occurring over a large retinal area ${ }^{6}$. On the other hand, in the presence of monocular cues, local 
stereopsis is used to evaluate horizontally disparate images in contour stereotests such as the Titmus Fly Stereotest (TFS) ${ }^{6,21}$. Stereopsis may be measured at distance and at near. In a study by Wong et al where monocular cues were eliminated and where they used the same tests at all distances, they found no significant change in stereoacuity with viewing distance ${ }^{21}$. As this stereoacuity is a threshold value for the distance at which it is measured, stereopsis is not effective beyond a certain critical distance ${ }^{3,21}$.

An important aspect of visual information relates to the perception of colour provided by the three types of photoreceptors in the retina. Light is interpreted as colour according to the wavelengths that strike the retina ${ }^{18}$. When light reaches a surface, it undergoes three main changes. Some of the light is reflected, some absorbed and the remainder transmitted ${ }^{18-20}$. A tinted lens possesses a definite colour and acts as a filter that alters the intensity and the spectral distribution of light that passes through it ${ }^{17-19}$. The colour of the tint is as a result of chemicals added to the spectacle lens to alter the transmission and absorption of the different wavelengths of visible light ${ }^{19,23-25}$.

Optometrists frequently prescribe tinted lenses for their patients. Tinted lenses are prescribed, inter alia, in the following circumstances: for the relief of photophobia ${ }^{26-28}$, to reduce asthenopic symptoms ${ }^{17,26}$, to decrease light scatter in conditions such as albinism, retinitis pigmentosa (RP) and cataracts ${ }^{29}$, to provide protection for people exposed to high levels of invisible radiation such as ultra-violet and infra-radiation ${ }^{19}$, to alleviate sensitivity to sunlight ${ }^{23,24}$, to improve the cosmesis in situations of disfigurements ${ }^{18}$, to enhance visual ergonomics ${ }^{17}$, to reduce glare from reflective surfaces such as snow, sand and water ${ }^{19}, 23$, as a placebo ${ }^{28}$, to improve colour perception in colour deficient individuals ${ }^{30}$ and to decrease light sensitivity in patients taking photosensitising drugs ${ }^{3}$.

Since different colour tints are generally used by patients under varying levels of illumination, ranging from bright sunlight to very poor light levels and in keeping with the more recent information regarding chromatic stereopsis mecha- nisms ${ }^{11}$, it is important to investigate the effect of these tinted lenses on stereopsis over a range of illumination levels. Tinted lenses are commonly available in a range of colours as either gradient or solid tints from grade A (light) to grade D (much darker). Illumination levels may be consistently decreased by using Gulden neutral density filters (ND) to allow for measuring stereopsis ranging from room illumination of 300 lux to measuring stereopsis under decreased light levels ( $<300$ lux $)^{24,25}$.

The aim of the study was to investigate the effects of reduced illumination and tinted lenses on stereopsis at near. The specific objectives were as follows:

i. to compare stereoacuity values across five levels of illumination (No ND filter, 0.3 ND, 0.6 $\mathrm{ND}, 0.9 \mathrm{ND}$ and 1.2 ND) without any lenses.

ii. to compare stereoacuity values using a white lens against a no lens condition across the five levels of illumination.

iii. to compare stereoacuity values using six tinted lenses at grade B against the no lens condition across the five levels of illumination.

\section{Methodology}

\section{Selection of participants}

A purposive sampling procedure was used to select sixty participants from the private practice of the clinician researcher (P Ramkissoon). This purposive sample comprised a non-probability cohort of participants who satisfied the inclusion criteria for this study. Adult participants ranging in age from 17 - 29 years were selected. Older adult participants were excluded in order to control for age-related changes in vision. A comprehensive eye examination (including measures of binocularity, that is, the cover test and fusional vergences) was used to screen all eligible participants to ensure that they satisfied the inclusion criteria for this study. Participants who had $<0.50 \mathrm{D}$ of astigmatism and $<0.50 \mathrm{D}$ sphere and monocular and binocular visual acuities of $6 / 6$ or better at distance and near were included, thus excluding bias accruing from compromised visual status. Participants with eye diseases and those who failed the Ishihara colour test were similarly 
excluded. Other exclusion criteria were poor general health status and intra-ocular pressure above $21 \mathrm{mmHg}$. There was no evidence in the literature suggesting the need to control for race and gender of participants.

\section{Lenses used}

A white CR 39 lens and six tinted lenses (CR39) were used on all participants in the study, namely, pink, blue, brown, grey, yellow and green. The depth of the solid tints used in this study was grade B. All the lenses were of zero power (plano) with a $2 \mathrm{~mm}$ standard centre thickness and equal transmittance, as measured on a spectrophotometer. Thus, all pertinent lens characteristics, including lens material, depth of tint, power, thickness and transmittance were controlled for in order to eliminate secondary variance. Stereopsis was assessed, for each participant, using a no lens condition and seven other lens conditions.

\section{Illumination levels}

Neutral density (ND) filters have been widely used in photography, cinematography and vision research to assess visual function under controlled levels of illumination ${ }^{24,25}$. Stereopsis was initially assessed under bright room illumination of 300 lux measured using a light meter, with ND filters (0.3 ND, 0.6 ND, 0.9 ND, and $1.2 \mathrm{ND}$ ) being subsequently used to decrease the level of illumination. Thus, stereopsis was assessed, for each participant, at five different levels of illumination.

\section{Stereoacuity test used}

Standard clinical tests for stereopsis include the TNO random-dot stereotest that does not have monocular cues based on the presence of contours, as well as the Titmus Fly Stereotest (TFS) that utilizes real contours, resulting in the presence of monocular cues. While the use of randot stimuli are generally considered the "gold standard" for measuring stereopsis, they are prone to false negative errors ${ }^{31}$. The TFS on the other hand has been shown to compare favourably to two randot tests under compromised levels of binocularity in young participants $^{32}$. Provided that the page is inverted to reverse the disparity, the TFS controls adequately for the presence of monocular cues ${ }^{31}$. Further, the TFS is a widely used clinical test that allows for rapid testing without significant subject fatigue, thereby yielding data that could inform clinical management decisions ${ }^{31}$. In the TFS, horizontal disparity is presented via the vectographic technique ${ }^{33}$. This test comprises three subtests, with the level of disparity decreasing progressively ${ }^{33}$. When tested at $40 \mathrm{~cm}$ the first subtest (the fly) has a disparity of $3600 \mathrm{sec}$ of arc, the second subtest (the rows of animals) has a disparity ranging from $400-100 \mathrm{sec}$ of arc and the third subtest (the Wirt rings) has a disparity ranging from 800 - $40 \mathrm{sec}$ of $\mathrm{arc}^{6}$. The ultimate measure of stereopsis is the participant's ability to discern the finest possible level of disparity. Given these considerations, the TFS was considered the measure of choice for this sample.

\section{Procedure}

Phase 1: Stereopsis measured under room illumination of 300 lux with no ND filter

Stereopsis was measured initially without any lenses (base line measure) followed by measurements through the white lens and then through each of the six tinted lenses, under normal room illumination, using the TFS. The order of presentation of tint condition was randomised to avoid treatment interaction effects. As recommended, this test was held at a test distance of $40 \mathrm{~cm}$ measured using a RAF rule. The participants viewed the targets binocularly using a pair of polarising spectacle lenses.

The first subtest, the fly, was shown to the participants who were asked to pinch the edge of the wings of the fly. The normal response was that the pinching fingers should be off the page by several centimetres.

In the second subtest comprising the three rows of animals, the participants were informed that all except one of the figures in each row remains flat. The participants were asked to indicate the animal that appeared raised in each 
row.

In the third subtest (a series of nine diamonds each of which contains four Wirt rings), one of the rings would be viewed at a different depth from the other three. The participants were asked to identify the ring that appeared to stand out from the page. The results were recorded in seconds of arc, corresponding to the last correctly identified circle/ animal.

As recommended by Garnham and Sloper ${ }^{31}$, the page was inverted in order to reverse the disparity, thus controlling for the effects of monocular cues. Each participant was allowed a fiveminute rest interval between measures in order to minimise fatigue effects. While the order of presentation of the three stereo subtests was maintained from subtest one to subtest three, the order of presentation within subtest two and three was randomised to avoid errors of habituation and expectancy, thus precluding guessing.

\section{Phase 2: Stereopsis measured under decreasing levels of illumination}

The second part of this study assessed stereopsis under decreasing levels of retinal illumination through the seven lens conditions. ND filters were placed binocularly over the no lens condition as well as with the seven tinted lenses and stereopsis was measured as per the procedure outlined in phase 1. Four ND filters $(0.3,0.6,0.9$ and 1.2) were used to decrease the luminance levels. A counterbalance design was used to control for possible confounding resulting from treatment interaction effects, where the order of presentation of luminance levels was randomised across the participants ${ }^{34}$.

\section{Data analysis}

Data was entered onto the Statistical Package for Social Scientists (SPSS), and a file audit was conducted to eliminate entry errors. Using general linear modelling, a repeated measures ANOVA was run, incorporating within-subjects factors at two levels viz. tint and illumination. This analysis rendered statistical comparison across tint by level of illumination, in line with the objectives of the study. The Bonferroni test was used for post-hoc multivariate analysis. In this multiple comparisons procedure, the familywise error (at $\alpha=5 \%$ ) was divided by the number of comparisons, thus controlling for Type I error by setting alpha at a more stringent level (the Bonferroni correction).

Table 1 demonstrates the progressive increase in mean stereoacuity scores (that is decline in stereopsis), for the no lens and each of the seven tint conditions, as the level of illuminance decreased from room illumination (0 ND) towards scotopic levels (1.2 ND). This pattern of results is confirmed in the multivariate analysis (Table 2), where a statistically significant difference was evident for the main effect of illumination $(F=119.706 ; \mathrm{df}=4 ; p=.000)$. Inspection of the means in Table 1 also reveals that, at each level of illumination, the stereoacuity scores for both the no lens and white lens conditions were consistently lower, that is better, than for each of the six other tint conditions.

Table 2 demonstrates a statistically significant difference for the main effect of tint $(F=8.996$; $\mathrm{df}=7 ; p=.000)$ as well as the interaction of illumination by tint $(F=4.760 ; \mathrm{df}=28 ; p=.000)$. The graphical illustration of these results (Figure 1), as well as the post-hoc analysis (Table 3), demonstrates specifically where these differences lie.

Table 3 shows no statistically significant difference in stereoacuity scores between the no lens and the white lens condition for each of the five levels of illumination ( $\mathrm{df}=59 ; p=.321 ; p$ $=.616 ; p=.047 ; p=.048 ; p=.167)$. Statistically significant differences were found between the no lens condition and each of the other six tints (pink, blue, brown, grey, yellow and green) at every level of illumination, thereby accounting for the statistically significant interaction effect reported in Table 2.

The main findings arising from the analysis of the data are that:

1. there was a significant decline in stereopsis as the level of illumination decreased, regardless of tint condition.

2. there was no statistically significant differ- 


\begin{tabular}{|c|c|c|c|c|c|}
\hline \multirow[t]{2}{*}{ Illumination } & \multirow[t]{2}{*}{ Tint } & \multirow[t]{2}{*}{ Mean } & \multirow[t]{2}{*}{ Std. Error } & \multicolumn{2}{|c|}{ 95\% Confidence Interval } \\
\hline & & & & Lower Bound & Upper Bound \\
\hline $0 \mathrm{ND}$ & $\begin{array}{l}\text { No lens } \\
\text { White Lens } \\
\text { Pink } \\
\text { Blue } \\
\text { Brown } \\
\text { Grey } \\
\text { Yellow } \\
\text { Green }\end{array}$ & $\begin{array}{l}42.721 \\
42.888 \\
46.667 \\
46.982 \\
45.881 \\
47.552 \\
46.379 \\
46.137\end{array}$ & $\begin{array}{l}.906 \\
.965 \\
1.227 \\
1.223 \\
1.381 \\
1.539 \\
1.347 \\
1.790\end{array}$ & $\begin{array}{l}40.890 \\
40.938 \\
44.187 \\
44.509 \\
43.090 \\
44.441 \\
41.050 \\
42.519\end{array}$ & $\begin{array}{l}44.553 \\
44.839 \\
49.146 \\
49.455 \\
48.672 \\
50.664 \\
48.707 \\
49.755\end{array}$ \\
\hline $0.3 \mathrm{ND}$ & $\begin{array}{l}\text { No lens } \\
\text { White Lens } \\
\text { Pink } \\
\text { Blue } \\
\text { Brown } \\
\text { Grey } \\
\text { Yellow } \\
\text { Green }\end{array}$ & $\begin{array}{l}67.339 \\
67.274 \\
75.329 \\
77.582 \\
75.031 \\
74.862 \\
72.862 \\
74.465\end{array}$ & $\begin{array}{l}2.108 \\
2.252 \\
2.461 \\
2.316 \\
2.526 \\
2.047 \\
3.246 \\
2.828\end{array}$ & $\begin{array}{l}63.079 \\
62.723 \\
70.354 \\
72.901 \\
69.925 \\
70.725 \\
66.302 \\
68.749\end{array}$ & $\begin{array}{l}71.600 \\
71.824 \\
80.303 \\
82.263 \\
80.137 \\
78.999 \\
79.422 \\
80.182\end{array}$ \\
\hline $0.6 \mathrm{ND}$ & $\begin{array}{l}\text { No lens } \\
\text { White Lens } \\
\text { Pink } \\
\text { Blue } \\
\text { Brown } \\
\text { Grey } \\
\text { Yellow } \\
\text { Green }\end{array}$ & $\begin{array}{l}123.519 \\
125.057 \\
172.845 \\
151.543 \\
154.767 \\
155.624 \\
157.510 \\
180.712\end{array}$ & $\begin{array}{c}4.874 \\
5.455 \\
9.266 \\
10.818 \\
9.160 \\
11.913 \\
5.928 \\
9.303\end{array}$ & $\begin{array}{l}113.667 \\
114.033 \\
154.119 \\
129.679 \\
136.254 \\
131.546 \\
145.528 \\
161.911\end{array}$ & $\begin{array}{l}133.371 \\
136.081 \\
191.572 \\
173.407 \\
173.280 \\
179.702 \\
169.491 \\
199.513\end{array}$ \\
\hline $0.9 \mathrm{ND}$ & $\begin{array}{l}\text { No lens } \\
\text { White Lens } \\
\text { Pink } \\
\text { Blue } \\
\text { Brown } \\
\text { Grey } \\
\text { Yellow } \\
\text { Green }\end{array}$ & $\begin{array}{l}189.205 \\
205.483 \\
280.893 \\
347.019 \\
403.940 \\
284.395 \\
267.898 \\
295.514\end{array}$ & $\begin{array}{l}13.519 \\
17.545 \\
29.499 \\
23.916 \\
28.822 \\
27.985 \\
24.464 \\
29.266\end{array}$ & $\begin{array}{l}161.883 \\
170.024 \\
221.273 \\
298.683 \\
345.690 \\
227.836 \\
218.454 \\
236.365\end{array}$ & $\begin{array}{l}216.527 \\
240.943 \\
340.512 \\
395.356 \\
462.191 \\
340.955 \\
317.341 \\
354.664\end{array}$ \\
\hline $1.2 \mathrm{ND}$ & $\begin{array}{l}\text { No lens } \\
\text { White Lens } \\
\text { Pink } \\
\text { Blue } \\
\text { Brown } \\
\text { Grey } \\
\text { Yellow } \\
\text { Green }\end{array}$ & $\begin{array}{c}598.000 \\
610.333 \\
860.119 \\
1002.095 \\
1157.262 \\
1022.619 \\
887.238 \\
1014.095\end{array}$ & $\begin{array}{c}62.781 \\
63.776 \\
98.672 \\
141.615 \\
131.507 \\
153.342 \\
114.713 \\
124.517\end{array}$ & $\begin{array}{l}471.116 \\
481.436 \\
660.695 \\
715.880 \\
891.477 \\
712.704 \\
655.394 \\
762.437\end{array}$ & $\begin{array}{c}724.884 \\
739.230 \\
1059.543 \\
1288.310 \\
1423.047 \\
1332.534 \\
1119.083 \\
1265.753\end{array}$ \\
\hline
\end{tabular}

ence in stereopsis between the no lens and white lens conditions at each level of illumination.

3. stereopsis was significantly superior with the no lens condition compared to all six other tint conditions (grade B), at each level of illumination.

\section{Discussion and Conclusions}

Information regarding the visual world is deduced based on the changes in the quantity and quality of light from a source and its interaction with matter such that one has to consider not only variations in the level of illumination, but variations in the spectral composition of light ${ }^{35}$. The response of the visual system (spectral sensitivity) to different light levels and colours is an inherent property of the type and distribution of the photoreceptors and neurons across the retina. Based on the difficulty experienced in seeing depth in isoluminant random-dot stereograms it was postulated that stereopsis is "colour-blind" and that therefore the information is most probably carried by the magnocellular system $^{35}$. However more current information suggests that there are two stereopsis mechanisms, one sensitive to luminance contrast 


\begin{tabular}{|c|c|c|c|c|c|}
\hline $\begin{array}{l}\text { Source (Sphericity } \\
\text { Assumed) }\end{array}$ & $\begin{array}{l}\text { Type III Sum of } \\
\text { Squares }\end{array}$ & $\mathrm{df}$ & Mean Square & $\mathrm{F}$ & Sig. \\
\hline illum & 202129922.333 & 4 & 50532480.583 & 119.706 & .000 \\
\hline Error (illum) & 99624752.667 & 236 & 422138.782 & & \\
\hline $\operatorname{tint}$ & 5535304.500 & 7 & 790757.786 & 8.996 & .000 \\
\hline Error(tint) & 36304320.500 & 413 & 87903.924 & & \\
\hline illum * tint & 10308889.667 & 28 & 368174.631 & 4.760 & .000 \\
\hline Error(illum*tint) & 127772035.333 & 1652 & 77343.847 & & \\
\hline
\end{tabular}

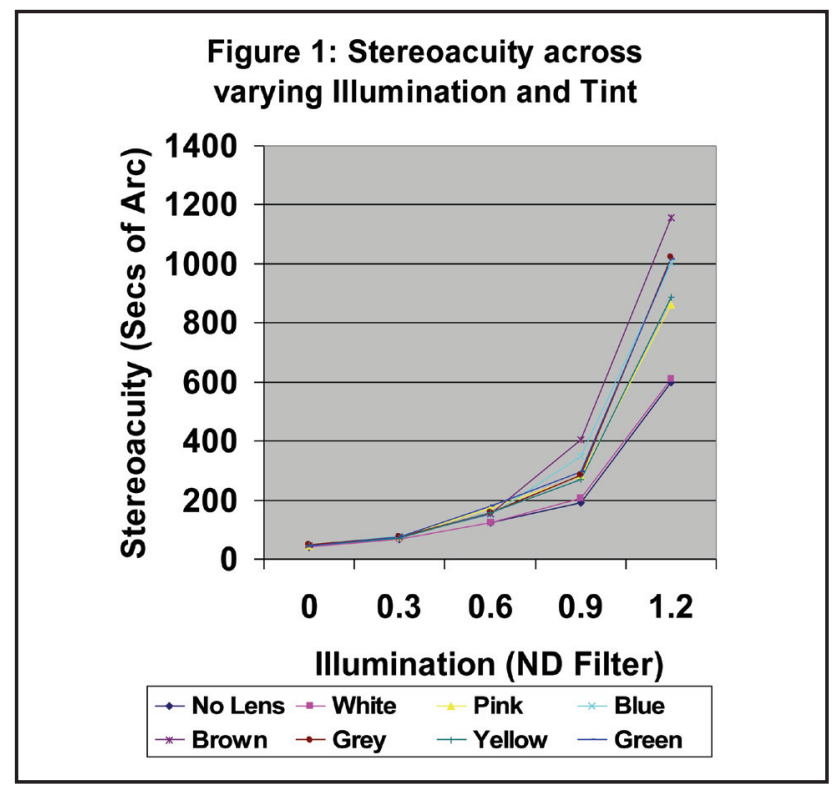

and the other to chromatic contrast ${ }^{11}$. It has been suggested that even though the disparity range of the luminance-contrast-sensitive mechanism is larger than that for the chromatic-contrast-sensitive mechanism, these two mechanisms must interact before the extraction of stereoscopic depth ${ }^{11}$. In fact, under certain conditions of poor stereopsis with luminance contrast alone, added isoluminant chromatic contrast does improve stereopsis significantly (probability summation) ${ }^{11}$. These findings formed the basis for this investigation into whether tinted lenses impacted negatively on stereopsis, as compared to no lens conditions, under decreasing levels of illumination.

The Duplicity Theory in vision states that, depending on the level of illumination, either the rods respond (scotopic light levels), both the rods and cones respond (mesopic light levels), or mainly the cones respond (photopic light levels) ${ }^{6}$. Since only the cones are responsible for chromatic sensitivity and this information is carried via the parvocellular system to the visual centers of the cortex, scotopic vision carries no information regarding the colour of objects ${ }^{1,6}$. Further, maximum visual acuity is possible in bright room illumination (300 lux) for central fixation when the cones alone respond ${ }^{6}$.

Figure 1 represents a composite illuminance response function of stereoacuity scores when various tinted lenses were used under varied retinal illuminance conditions. As shown in Figure 1 , neutral density filters worsened retinal illuminance and consequently the stereoacuity (that is, the threshold values increased) for all lenses tested as well as when no (tinted) lens was used. The greater the density of the filter, the greater was the reduction in stereoacuity. This meant that as illumination was reduced, stereopsis worsened similar to other studies which compared the rapid decline in stereopsis as opposed to visual acuity under poor light conditions ${ }^{15,36}$. While the decline was relatively steady up to the level of illumination decreased by the $0.9 \mathrm{ND}$, the illumination level between 0.9 ND and 1.2 ND resulted in a dramatic increase in the stereoacuity scores suggesting very poor stereopsis. It is highly likely that whilst stereopsis under scotopic conditions is possible ${ }^{15}$, rod vision does not adequately support stereopsis in the absence of the additive effect of the chromatic mechanism of stereopsis ${ }^{11}$. These results therefore support the luminance contrast sensitive stereopsis mechanisms. Inspection of the marginal means reveals that at $1.2 \mathrm{log}$ units, yellow and pink perform better than the other four tints. Even though it has been shown that yellow tinted lenses do not improve visual acuity, stereopsis or contrast sensitivity, they are found to enhance brightness based on rod signals car- 


\begin{tabular}{|c|c|c|c|c|c|c|c|}
\hline \multicolumn{2}{|c|}{ Pairings } & \multirow[t]{2}{*}{ Mean } & \multirow[t]{2}{*}{ Std. Deviation } & \multirow[t]{2}{*}{ Std. Error } & \multirow[t]{2}{*}{$t$} & \multirow[t]{2}{*}{$\mathrm{df}$} & \multirow[t]{2}{*}{ Sig. (2-tailed)* } \\
\hline Illumination & Tint & & & & & & \\
\hline No ND & $\begin{array}{l}\text { no lens - white } \\
\text { no lens - pink } \\
\text { no lens - blue } \\
\text { no lens - brown } \\
\text { no lens - grey } \\
\text { no lens - yellow } \\
\text { no lens - green }\end{array}$ & $\begin{array}{l}-.333 \\
-3.667 \\
-4.167 \\
-3.500 \\
-4.667 \\
-3.509 \\
-3.500\end{array}$ & $\begin{array}{l}2.582 \\
7.584 \\
5.612 \\
6.846 \\
7.471 \\
6.932 \\
6.915\end{array}$ & $\begin{array}{l}.333 \\
.979 \\
.725 \\
.884 \\
.965 \\
.902 \\
.897\end{array}$ & $\begin{array}{l}-1.000 \\
-3.745 \\
-5.751 \\
-3.960 \\
-4.838 \\
-3.908 \\
-3.927\end{array}$ & $\begin{array}{l}59 \\
59 \\
59 \\
59 \\
59 \\
59 \\
59\end{array}$ & $\begin{array}{l}.321 \\
.000^{* *} \\
.000^{* *} \\
.000^{* *} \\
.000^{* *} \\
.000^{* *} \\
.000^{* *}\end{array}$ \\
\hline $0.3 \mathrm{ND}$ & $\begin{array}{l}\text { no lens - white } \\
\text { no lens - pink } \\
\text { no lens - blue } \\
\text { no lens - brown } \\
\text { no lens - grey } \\
\text { no lens - yellow } \\
\text { no lens - green }\end{array}$ & $\begin{array}{l}-.500 \\
-9.000 \\
-9.333 \\
-8.667 \\
-8.500 \\
-7.333 \\
-8.333\end{array}$ & $\begin{array}{c}7.686 \\
12.849 \\
12.604 \\
13.957 \\
14.001 \\
16.351 \\
13.550\end{array}$ & $\begin{array}{l}.992 \\
1.659 \\
1.627 \\
1.802 \\
1.807 \\
2.111 \\
1.749\end{array}$ & $\begin{array}{l}-.504 \\
-5.426 \\
-5.736 \\
-4.810 \\
-4.703 \\
-3.474 \\
-4.764\end{array}$ & $\begin{array}{l}59 \\
59 \\
59 \\
59 \\
59 \\
59 \\
59\end{array}$ & $\begin{array}{l}.616 \\
.000^{* *} \\
.000^{* *} \\
.000^{* *} \\
.000^{* *} \\
.001^{* *} \\
.000^{* *}\end{array}$ \\
\hline $0.6 \mathrm{ND}$ & $\begin{array}{l}\text { no lens - white } \\
\text { no lens - pink } \\
\text { no lens - blue } \\
\text { no lens - brown } \\
\text { no lens - grey } \\
\text { no lens - yellow } \\
\text { no lens - green }\end{array}$ & $\begin{array}{l}-3.667 \\
-35.667 \\
-35.333 \\
-34.333 \\
-36.667 \\
-30.667 \\
-41.667\end{array}$ & $\begin{array}{l}14.018 \\
64.318 \\
52.253 \\
52.863 \\
63.691 \\
31.346 \\
68.325\end{array}$ & $\begin{array}{l}1.810 \\
8.303 \\
6.746 \\
6.825 \\
8.222 \\
4.047 \\
8.821\end{array}$ & $\begin{array}{l}-2.026 \\
-4.295 \\
-5.238 \\
-5.031 \\
-4.459 \\
-7.578 \\
-4.724\end{array}$ & $\begin{array}{l}59 \\
59 \\
59 \\
59 \\
59 \\
59 \\
59\end{array}$ & $\begin{array}{l}.047 \\
.000 * * \\
.000 * * \\
.000 * * \\
.000^{* *} \\
.000^{* *} \\
.000 * *\end{array}$ \\
\hline $0.9 \mathrm{ND}$ & $\begin{array}{l}\text { no lens - white } \\
\text { no lens - pink } \\
\text { no lens - blue } \\
\text { no lens - brown } \\
\text { no lens - grey } \\
\text { no lens - yellow } \\
\text { no lens - green }\end{array}$ & $\begin{array}{c}-15.333 \\
-109.667 \\
-128.000 \\
-131.333 \\
-104.667 \\
-98.667 \\
-114.333\end{array}$ & $\begin{array}{c}58.729 \\
165.887 \\
172.173 \\
177.761 \\
168.719 \\
142.988 \\
135.651\end{array}$ & $\begin{array}{c}7.582 \\
21.416 \\
22.227 \\
24.769 \\
21.781 \\
18.460 \\
17.512\end{array}$ & $\begin{array}{l}-2.022 \\
-5.121 \\
-5.759 \\
-5.693 \\
-4.805 \\
-5.345 \\
-6.529\end{array}$ & $\begin{array}{l}59 \\
59 \\
59 \\
59 \\
59 \\
59 \\
59\end{array}$ & $\begin{array}{l}.048 \\
.000^{* *} \\
.000^{* *} \\
.000^{* *} \\
.000^{* *} \\
.000^{* *} \\
.000^{* *}\end{array}$ \\
\hline $1.2 \mathrm{ND}$ & $\begin{array}{l}\text { no lens - white } \\
\text { no lens - pink } \\
\text { no lens - blue } \\
\text { no lens - brown } \\
\text { no lens - grey } \\
\text { no lens - yellow } \\
\text { no lens - green }\end{array}$ & $\begin{array}{l}-16.667 \\
-283.333 \\
-443.333 \\
-443.333 \\
-425.000 \\
-270.000 \\
-430.000\end{array}$ & $\begin{array}{c}92.364 \\
446.898 \\
802.616 \\
793.270 \\
840.223 \\
550.901 \\
714.807\end{array}$ & $\begin{array}{c}11.924 \\
57.694 \\
103.617 \\
102.411 \\
108.472 \\
71.121 \\
92.281\end{array}$ & $\begin{array}{l}-1.398 \\
-4.911 \\
-4.279 \\
-4.329 \\
-3.918 \\
-3.796 \\
-4.660\end{array}$ & $\begin{array}{l}59 \\
59 \\
59 \\
59 \\
59 \\
59 \\
59\end{array}$ & $\begin{array}{l}.167 \\
.000 * * \\
.000^{* *} \\
.000^{* *} \\
.000^{* *} \\
.000^{* *} \\
.000^{* *}\end{array}$ \\
\hline
\end{tabular}

rying the information along the chromatic channels and amongst other optical explanations, a selective reduction of short-wavelength light has been posited ${ }^{37-39}$. This study indictates the need for further research to investigate between-colour comparisons using a range of tints and depths of tints as well as photochromic lenses under different levels of illumination.

Since the white lens performed as well as the no-lens condition under the different levels of illumination, but both differed statistically significantly from all the other six tinted lenses at each of the levels of illumination, it is evident that the tinted lenses adversely affected stereopsis at near under reduced levels of illumination.

As it is necessary to constantly distinguish objects in the environment at varying distances, any change in stereoacuity induced by tinted lenses will influence visually guided performance. Luria $^{39}$ also found that depth perception was diminished with tinted lenses; his proposal that the reduced transmittance produced by tinted lenses decreased the stereoacuity is corroborated by the findings of this study. Therefore, the practitioner should ensure that tinted lenses prescribed do not retard stereoacuity in circumstances where good stereoacuity is required ${ }^{3}$. In advising a patient concerning tinted lenses, the practitioner should question the patient not only on his sensitivity to light, but also as to the activities and levels of illumination for which the lenses are to be used ${ }^{27}$.

Pitts and $\mathrm{Chou}^{3}$ advised that care must be taken to ensure that the tint does not impair vision if industrial workers move quickly or frequently 
from brilliant sunlight into a dimly lighted environment. The optometrist must have available a range of tinted lenses that would be suitable for the environment in which the wearer works or intends to use the spectacles ${ }^{25,27}$. When stereopsis is affected by tinted lenses under poor light levels, depth perception may still be appreciated using monocular cues and luminance contrast mechanisms and the individual's performance may not be significantly compromised. However, certain vocations require good depth perception and since stereopsis has been found to be the most superior cue to depth perception up to 450 metres, it is important that optometrists offer the best possible advice to these patients.

It would be valuable to compare the levels of stereopsis using a range of solid tints from A to $\mathrm{D}$ as well comparing the effects of gradient tints to solid tints. Clinically important information would be available if the stereopsis could be evaluated while performing dynamic critical tasks to assess the severity of the effects of the decrease in stereopsis on performance under different light levels.

\section{References}

1. Hubel DH. Eye, Brain and Vision. 2nd ed. New York: WH Freeman and Company, 1995.

2. Barton RA. Binocularity and brain evolution in primates. Proc Natl Acad Sci 2004101 10113-10115.

3. Benjamin WJ. Clinical Refraction. 1st ed. Philadelphia: WB Saunders Company, 1998.

4. DeAngelis GC. Seeing in three dimensions: the neurophysiology of stereopsis. Trends Cogn Sci 20004 80-90.

5. Griffin J. Binocular Anomalies, Procedures for Vision Therapy, 2nd ed. New York: Professional Press Books, 1988.

6. Webvision. Available from: URL: http://webvision.med.utah. edu/KallDepth.html.

7. Vision and Colour. Available from URL: http://www.du.edu/ $\sim$ jcalvert/optics/colour.htm\#Ster

8. Long J, Siu C. Randot stereoacuity does not accurately predict ability to perform two practical tests of depth perception at a near distance. Optom Vis Sci 200582 912-915.

9. Daw NW. Visual Development. 1st ed. New York: Plenum Press, 1995.

10. Simmons DR and Kingdom FAA. On the independence of chromatic and achromatic stereopsis mechanisms. Vision Res 199737 1271-1280.

11. Simmons DR and Kingdom FAA. Interactions between chromatic and luminance contrast sensitive stereopsis mechanisms. Vision Res 200242 1535-45.

12. Chang YH, Lee JB, Kim NS, Lee DW, Chang JH and Han SH. The effects of interocular differences in retinal illuminance on vision and binocularity. Clin Exp Ophthalmol 2006244 1083-8.

13. Lovasik JV and M Szymkiw. Effects of aniseikonia, anisometro- pia, accommodation, retinal illuminance, and pupil size on stereopsis. Inves Ophthal Vis Sci 198526 741-750.

14. Lit A, Dwyer WO and Morandi AJ. Effect of background wavelength on stereoscopic acuity at scotopic and photopic illumination levels. Am J Optom 196845 195-203.

15. Livingston MS and Hubel DH. Stereopsis and positional acuity under dark adaptation. Vision Res 199434 799-802.

16. Elkington AR, Frank HJ. Clinical Optics. 2nd ed. London: Blackwell Scientific Publications, 1984.

17. Edwards K, Llewellyn R. Optometry. 1st ed. London: Butterworths, 1988.

18. Brooks CW, Borish IM. System for Ophthalmic Dispensing: London: Butterworth-Heineman, 1979.

19. Jalie M. The Principles of Ophthalmic Lenses. 4th ed. London: Association of Dispensing Opticians, 1984.

20. Lehmann OJ, Verity DH, Coombes AGA, Ah-Fat FG, Francis PJ, Ionides ACW. Clinical Optics and Refraction. 1st ed. Oxford: Butterworth-Heinemann, 1998.

21. Wong BPH, Woods RL, Peli E. Stereoacuity at distance and near. Optom Vis Sci 200279 771-778.

22. Bhola R. Binocular Vision. Available from: URL: http://webeye. ophth.uiowa.edu/eyeforum/tutorials/Bhola-BinocularVision.htm.

23. Borish IM. Clinical Refraction. 3rd ed. Chicago: Professional Press, 1970.

24. Drew R. Professional Ophthalmic Dispensing. Chicago: Professional Press Inc. 1970.

25. Drew R. Ophthalmic Dispensing. The present-day realities. London: Butterworths, 1990.

26. Fannin TE, Grosvenor TG. Clinical Optics. Boston: Butterworths, 1987.

27. Hickson-Curran SB, Nasson RJ, Becherer PD. Clinical evaluation of Acuvue Contact Lenses with UV blocking characteristics. Optom Vis Sci 199774 632-637.

28. Kirkner R. Using contrast sensitivity testing in practice. Rev Optom 1331996 139-140.

29. Eperjesi F, Fowler CW and Evans BJW. Do tinted lenses or filters improve visual performance in low vision? A review of literature. Ophthal Physio Optics 200222 68-77.

30. Peli E. Treating with spectacle lenses: A novel idea? Optom Vis Sc 200279 569-580.

31. Garnham L and Sloper JJ. Effect of age on adult stereoacuity as measured by different types of stereotest. Br J Ophthal 200690 91-95.

32. Fawcett SL and Birch E. Validity of the Titmus and Randot circles tasks in children with known binocular vision disorders. $J$ APPOS 20037 333-8.

33. Fricke TR and Siderov J. Stereopsis, stereotest and their relation to vision screening and clinical practice. Clin Exp Optom 1997 80165 - 172.

34. Robinson, P.W. Fundamentals of Experimental Psychology, 2nd ed., Prentice-Hall, New Jersey 1981.

35. Spillman L and Werner JS. Visual Perception: The Neurophysiological Foundations. London: Academic Press, 1990.

36. Rabin J. Luminance effects on visual acuity and small letter contrast sensitivity. Optom Vis Sci 1994 71 685-688.

37. Kelly S. Effect of yellow-tinted lenses on brightness. J Opt Soc Am 19907 1905-1911.

38. Wolffsohn JS, Cochrane AL, Khoo H, Yoshimitsu Y, Wu S. Contrast is enhanced by yellow lenses because of selective reduction of short-wavelength light. Optom Vis Sci 200077 73-81.

39. Luria SM. Vision with chromatic filters. Am J Optom 197249 818-829. 